\title{
Crescimento econômico sustentável ou novamente o vôo da galinha?
}

\section{Introdução}

Luciano Nakabashi* Marcelo Curado ${ }^{* *}$

O objetivo do presente estudo é analisar o efeito da queda dos juros sobre o desempenho da economia brasileira. Essa mudança de cenário é fundamental para que a economia brasileira possa atingir taxas de crescimento econômico que sejam sustentáveis e em um nível que estejam na média ou acima dela quando comparada com o crescimento da economia mundial.

No entanto, devido à armadilha em que se encontra a economia brasileira, no qual o processo de crescimento da demanda pode gerar elevações nos preços e, portanto, induzir o Banco Central a abortar tal processo, é muito provável que não será em um futuro próximo que iremos assistir ao tão esperado processo de crescimento econômico sustentável.

2. Taxa de juros e seus efeitos no desempenho econômico brasileiro: 2001-

Com grande ajuda do desempenho da economia mundial, a economia brasileira tem apresentado uma perceptível melhora nos seus principais indicadores econômicos. O bom desempenho do setor exportador teve impactos positivos nas contas externas, reduzindo a vulnerabilidade da economia em relação a choques externos.

Esse melhora nas contas externas, aliada a uma elevada taxa de juros, aumenta a oferta de dólares de forma a valorizar o câmbio, o que se traduz em uma redução do preço dos produtos importados. A valorização do câmbio contribui, dessa forma, para o controle da inflação. Dados do Banco Central informam que este efeito do câmbio cumpriu nos últimos dois anos um papel relevante na manutenção da estabilidade de preços.

Com uma economia mais robusta em relação a choques externos e com a inflação controlada (Figura 1), os gestores do Banco Central do Brasil perceberam que era possível se iniciar um processo de redução da taxa de juros. Também podemos ver que após a taxa de juros nominal (taxa de juros anual - Selic - fixada pelo Copom) atingir um pico de 19,75\%, no período de junho a setembro de 2005 , iniciou-se um processo de queda dessa variável. A taxa

\footnotetext{
* Doutor em economia pelo CEDEPLAR/UFMG e professor adjunto do Departamento de Economia da UFPR. Endereço eletrônico: nakabashi@ufpr.br

** Doutor em economia pela UNICAMP, chefe e professor adjunto do Departamento de Economia da UFPR. Endereço eletrônico: mcurado@ufpr.br.
} 
de juros real, ou seja, taxa de juros nominal descontada pela expectativa média de inflação (IPCA - taxa acumulada para os próximos doze meses) seguiu um padrão semelhante:

Figura 1. Expectativa da inflação e taxas de juros nominais e reais

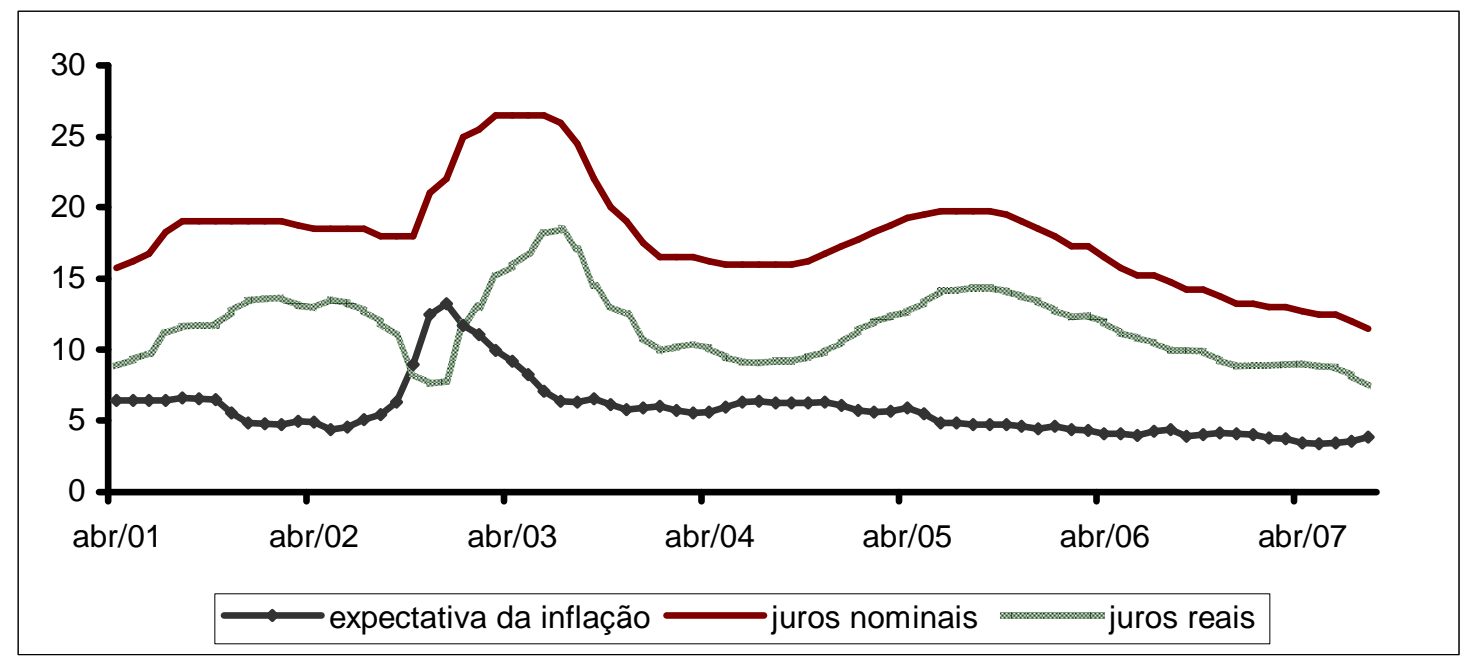

Fonte: Elaboração própria a partir de dados do Banco Central do Brasil

Tal processo é essencial no estímulo ao crescimento, considerando seus impactos positivos sobre o nível de investimentos e de consumo de bens duráveis.

De fato, com o começo do processo de redução dos juros, em meados de 2005, os efeitos positivos sobre a economia começaram a ser sentidos já em 2006. Utilizando dados trimestrais, na Figura 2, podemos constatar uma leve melhora na taxa de crescimento do PIB nos trimestres dos anos de 2006 e 2007 em relação aos trimestres de 2005. Enquanto a média da taxa trimestral de crescimento do PIB em 2005 foi de 0,77\%, em 2006 e 2007 elas foram de $1,17 \%$ e de $0,84 \%$, respectivamente.

$\mathrm{Na}$ Figura 3 estão apresentadas as diferenças da taxa de crescimento do PIB de cada setor em relação à taxa de crescimento do PIB da economia como um todo. Pode-se notar que a indústria e, em particular, a indústria de transformação foram as mais beneficiadas a partir do final de 2006. 
Figura 2. Taxa real trimestral de crescimento do PIB do Brasil

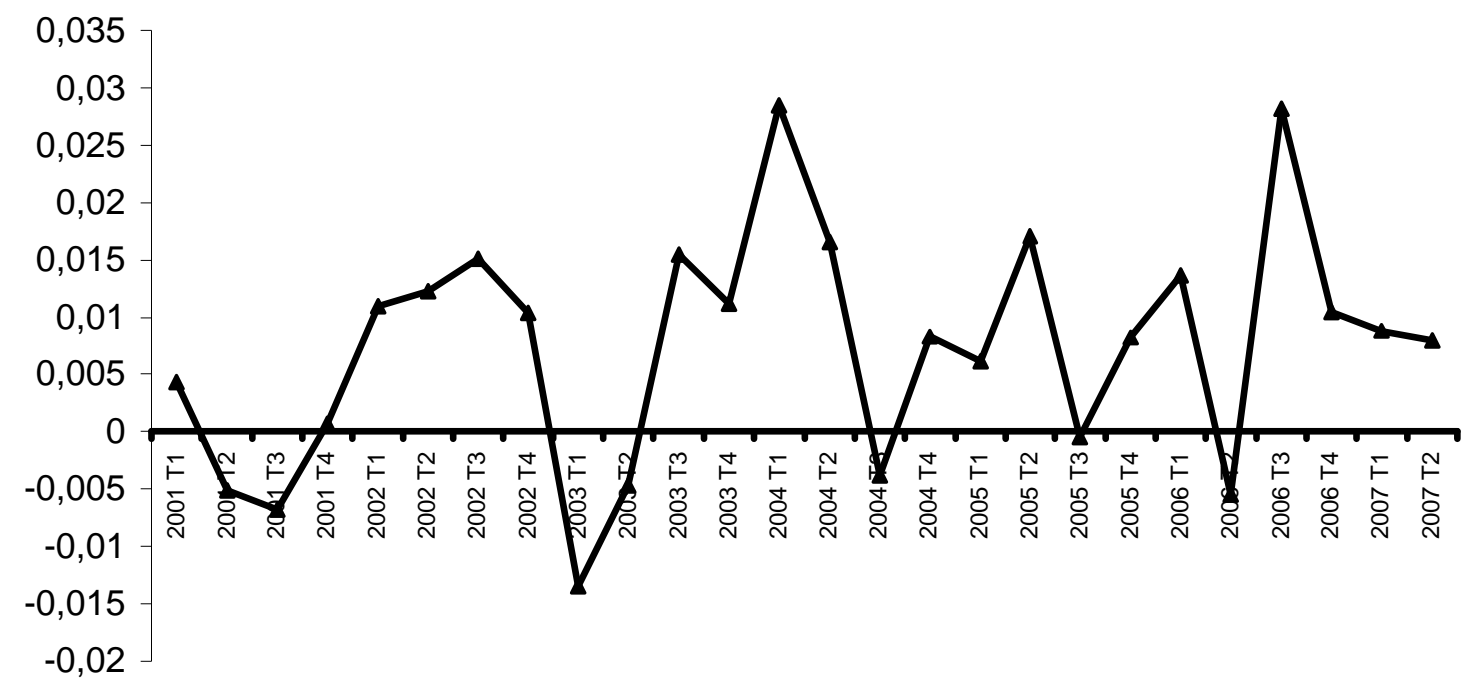

Fonte: Elaboração própria a partir de dados do Sistema de Contas Nacionais Trimestrais Referência 2000 (dados oriundos do banco Sidra) - IBGE

Figura 3. Diferença da taxa real trimestral de crescimento de cada um dos setores da economia em relação à taxa de crescimento do PIB

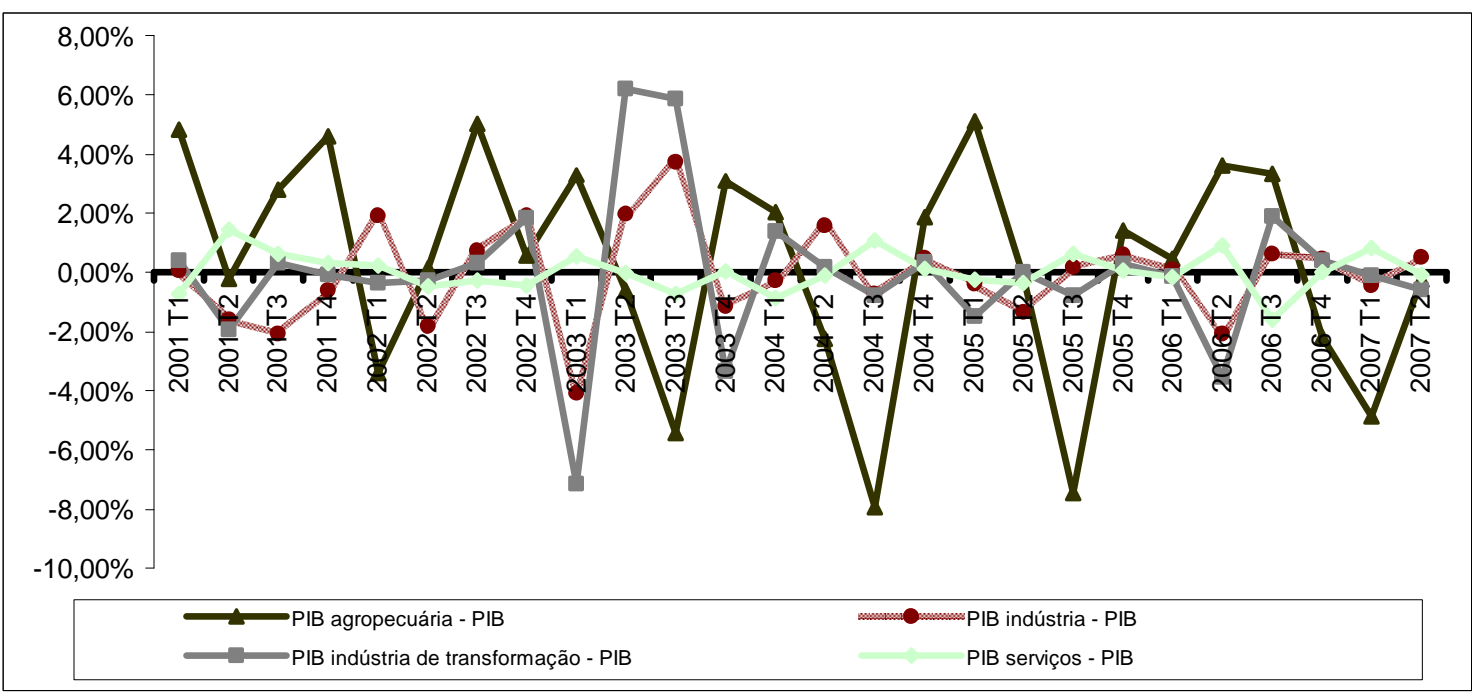

Fonte: elaboração própria a partir de dados do Sistema de Contas Nacionais Trimestrais Referência 2000 (dados oriundos do banco Sidra) - IBGE.

Obviamente, existem outras variáveis que são importantes na determinação do desempenho do PIB da economia e do PIB de cada um de seus setores, além da taxa de juros. No entanto, dada a importância desta na tomada de decisão de investimentos por parte dos empresários, é muito improvável que a queda dos juros não esteja afetando seu crescimento.

CURADO e NAKABASHI (2007) mostraram algumas evidências de que a taxa de câmbio é outra variável relevante na decisão de investimentos dos empresários e, desse modo, 
no desempenho de cada um de seus setores. Adicionalmente, eles mostraram que os efeitos da valorização cambial parecem estar afetando negativamente o desempenho da indústria total e de transformação na margem, ou seja, seus efeitos só começaram a ser sentidos de uma maneira mais evidente a partir de 2005.

Os resultados parecem contraditórios. Isso ocorre devido à diferença nos dados utilizados por CURADO e NAKABASHI (2007) e aqueles empregados no presente estudo. Enquanto, no primeiro, os dados são anuais e as séries terminam em 2006, neste, os dados são trimestrais e vão até o segundo trimestre de 2007. Como a recuperação das participações da indústria e indústria de transformação no PIB da economia ocorreu a partir do final de 2006, o estudo de CURADO e NAKABASHI (2007) não foi capaz de capturar esse efeito.

Como a taxa de câmbio real ficou praticamente estável desde meados de 2005 até meados de 2007 (Figura 4), a recuperação do PIB da economia se deve, provavelmente, a queda dos juros que começou, justamente, em meados de 2005.

Figura 4. Taxa efetiva de câmbio real - 01/2001 a 08/2007

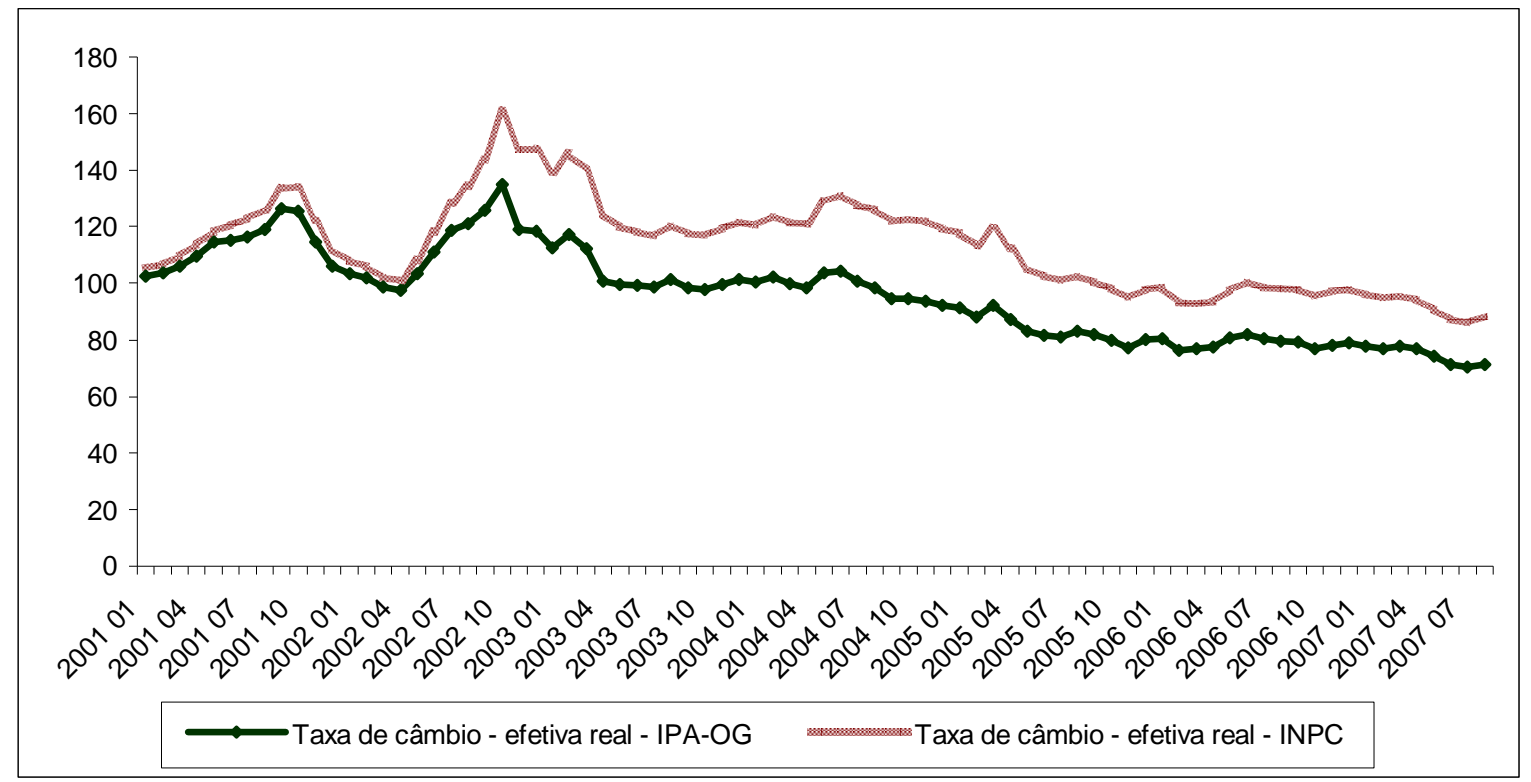

Fonte: Elaboração própria a partir de dados do IPEA.

Assim, a queda dos juros está, em certa medida, aliviando os efeitos negativos do câmbio valorizado no desempenho econômico brasileiro. Boa parte dos efeitos do câmbio valorizado parece ter sido absorvido, enquanto que as implicações da queda dos juros estão começando a transparecer.

As evidências dessa retomada ficam ainda mais claras quando se analisam os dados relativos às contratações realizadas no setor formal da economia. Analisando a ampliação dos 
números de vínculos empregatícios no acumulado de janeiro a agosto de cada ano, ao longo dos últimos cinco anos (Tabela 1), observamos que, no Brasil, as contratações líquidas (admissões descontadas as demissões) em 2007 ficam atrás apenas dos números de 2004, ano em que a economia brasileira alcançou a maior taxa de crescimento da década.

Tabela 1. Evolução do número de contratações líquidas no setor formal da economia brasileira - Acumulado jan/ago (2003-2007)

\begin{tabular}{llllll}
\hline \multirow{2}{*}{ Atividade } & \multicolumn{5}{c}{ Período } \\
\cline { 2 - 6 } & $\mathbf{2 0 0 3}$ & $\mathbf{2 0 0 4}$ & $\mathbf{2 0 0 5}$ & $\mathbf{2 0 0 6}$ & $\mathbf{2 0 0 7}$ \\
\hline Total & 677.912 & 1.466 .446 & 1.219 .236 & 1.207 .070 & 1.355 .824 \\
1.Extrat mineral & 5.465 & 8.271 & 8.316 & 10.088 & 8.110 \\
2.Indust transformação & 137.361 & 454.555 & 218.331 & 264.663 & 367.904 \\
3.Serv ind ut pub & 2.081 & 6.671 & 9.980 & 9.531 & 6.465 \\
4.Construcao civil & -14.000 & 90.057 & 91.206 & 118.839 & 142.743 \\
5.Comercio & 94.183 & 214.875 & 205.361 & 129.979 & 161.160 \\
6.Servicos & 210.397 & 383.520 & 453.530 & 441.615 & 424.671 \\
7.Adm publica & 20.614 & 26.964 & 33.061 & 26.753 & 29.154 \\
8.Agric.silvicult & 220.986 & 281.477 & 199.400 & 205.602 & 215.617 \\
9.Outros & 825 & 56 & 51 & 0 & 0 \\
\hline
\end{tabular}

Fonte: Elaboração própria a partir dos dados do CAGED (2007)

As contratações líquidas da indústria de transformação seguiram um padrão semelhante. No entanto, a retomada na geração líquida de empregos na indústria de transformação foi maior quando comparada com a criação líquida de empregos da economia como um todo. Isso fica claro de acordo com os dados apresentados na Figura 5, considerando os anos de 2006 e 2007 em relação ao ano de 2005.

O acompanhamento do desempenho da indústria e indústria de transformação é de extrema relevância, considerando o fato de que o desempenho desses setores pode ser fundamental na dinâmica de longo prazo da economia brasileira.

KALDOR (1957) enfatiza a importância da indústria sobre o crescimento econômico, visto os efeitos positivos gerados pelos investimentos realizados nesta na determinação do nível de tecnologia. Isso acontece porque, em muitos casos, há uma nova tecnologia incorporada nas novas máquinas e equipamentos e esse fenômeno é ainda mais importante no setor industrial ${ }^{13}$.

13 Keller (2004) enfatiza que tal efeito é amplificado em economias abertas, pois o comércio internacional disponibiliza bens que incorporam conhecimento externo, fornecendo tecnologia que, de outro modo, não estaria disponível ou que seria muito mais custosa para ser obtida. 
Figura 5. Participação da geração líquida de empregos na indústria de transformação na criação total líquida de empregos - no acumulado de jan/ago (2003-2007)

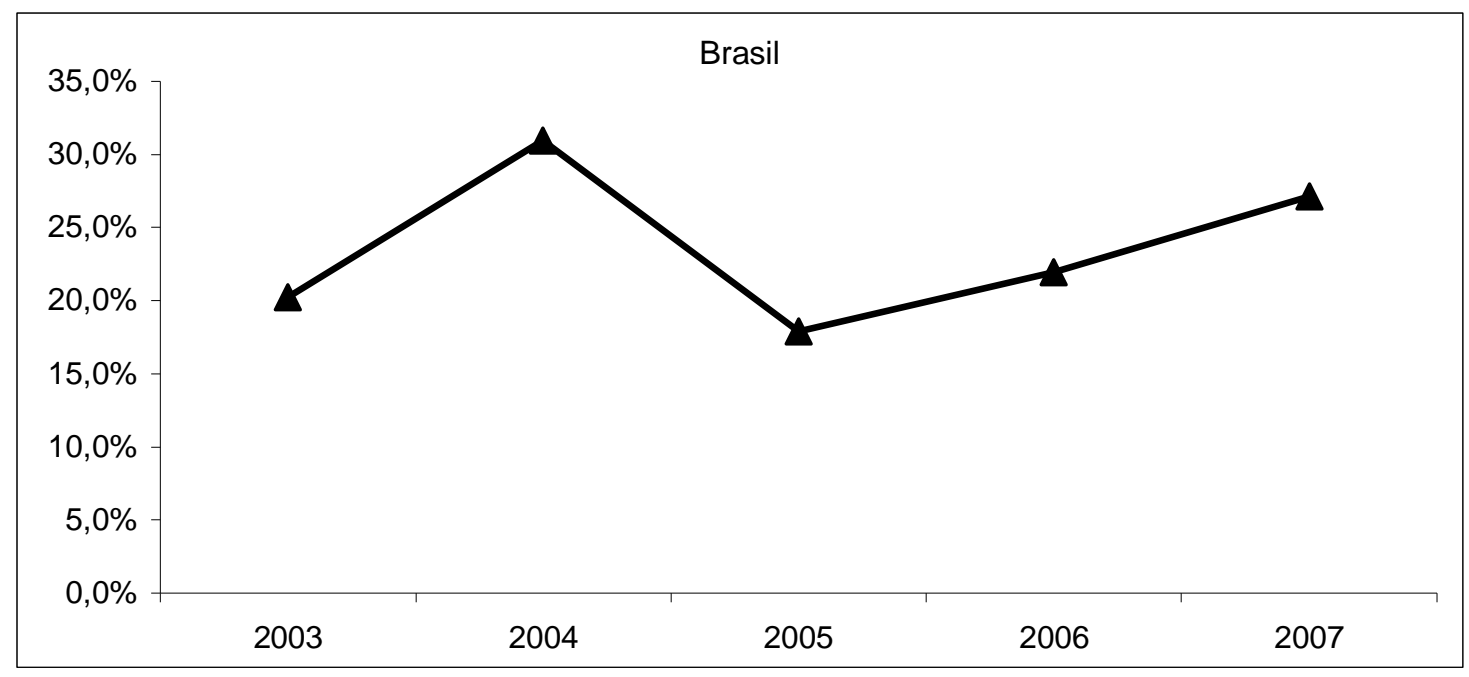

Fonte: Elaboração própria a partir dos dados do CAGED (2007)

\section{inflacionárias?}

3. Até que ponto será possível reduzir os juros sem criar pressões

A condição para o crescimento sem inflação é a existência de investimentos, em períodos anteriores, de forma a criar capacidade produtiva. No entanto, devido ao elevado nível dos juros no passado recente, a maior parte dos recursos foram aplicados no mercado financeiro sem causar, desse modo, impactos relevantes na capacidade produtiva da economia brasileira.

Mesmo que a redução dos juros estimule os investimentos, há um certo período de maturação destes até que se tornem, de fato, produtivos. Esse tempo pode ser maior ou menor dependendo do tipo e setor em que os investimentos são realizados. De uma forma geral o que é preocupante é que os investimentos em setores de infra-estrutura (transportes e energia, por exemplo) têm um prazo de maturação bastante elevado.

Em suma, o primeiro impacto da redução dos juros é sobre o aumento da demanda e, na medida em que a capacidade ociosa das empresas diminui, ocorre uma pressão para elevação dos preços dos bens e serviços.

Além dessa pressão inflacionária na economia brasileira causada pela queda da taxa de juros, o aumento da demanda externa e dos gastos do governo também estão pressionando os preços. Segundo dados do Boletim de Conjuntura do IPEA, a inflação acumulada dos alimentos, nos últimos 12 meses, foi de 9,3\% (Tabela 2) e o gasto primário total do governo 
central se elevou em 9,4\%, nos primeiros sete meses de 2007 em relação ao mesmo período do ano anterior.

Tabela 2. Índice de Preços ao Consumidor (taxa mensal, em \%)

\begin{tabular}{|c|c|c|c|c|c|c|}
\hline & \multicolumn{4}{|c|}{ Variação } & \multirow{2}{*}{$\begin{array}{l}\text { Impacto } \\
\text { em p.p. } \\
\text { Ago./2007 }\end{array}$} & \multirow{2}{*}{$\begin{array}{l}\text { Acumulado } \\
\text { em } 12 \text { meses }\end{array}$} \\
\hline & Ago./2006 & Jun./2007 & Jul./2007 & Ago./2007 & & \\
\hline Indice geral & 0,05 & 0,28 & 0,24 & 0,47 & 0,47 & 4,18 \\
\hline Alimentação & 0,07 & 1,09 & 1,27 & 1,39 & 0,29 & 9,30 \\
\hline Habitação & 0,11 & 0,25 & $-0,74$ & 0,05 & 0,01 & 1,39 \\
\hline Artigos & $-0,14$ & $-0,65$ & $-0,39$ & 0,08 & 0,00 & $-2,58$ \\
\hline Vestuário & 0,09 & 0,91 & $-0,16$ & $-0,03$ & 0,00 & 4,10 \\
\hline Transportes & $-0,32$ & $-0,40$ & $-0,08$ & 0,05 & 0,01 & 1,94 \\
\hline Saúde & 0,20 & 0,32 & 0,33 & 0,31 & 0,03 & 4,40 \\
\hline Despesas & 0,96 & 0,42 & 0,52 & 0,59 & 0,06 & 7,40 \\
\hline Educação & $-0,02$ & 0,04 & 0,06 & 0,38 & 0,03 & 4,55 \\
\hline Comunicação & $-0,30$ & $-0,05$ & 0,42 & 0,71 & 0,04 & 1,00 \\
\hline
\end{tabular}

Fonte: IPEA utilizando dados do IBGE

De fato, segundo dados do mesmo relatório, enquanto a inflação acumulada em 12 meses atingiu a marca de 3\%, no final do primeiro trimestre de 2007 , ela chegou a $4,2 \%$ (Tabela 2), em agosto passado. Portanto, a economia brasileira encontra-se em uma armadilha na qual o processo de crescimento da demanda pode gerar elevações nos preços. Estamos pagando pelos baixos níveis de investimento produtivo dos últimos anos.

Como a taxa de juros é o principal instrumento de controle inflacionário, a autoridade monetária logo encerrará o seu processo de queda e, como essa taxa ainda se encontra em um patamar muito elevado, os estímulos ao crescimento não serão suficientes para que a economia brasileira mantenha razoáveis taxas de crescimento sem depender do bom desempenho da economia mundial.

É preciso lembrar também que os efeitos da taxa de juros sobre a demanda agregada não são imediatos. No caso brasileiro, o Banco Central trabalha com a hipótese de que a redução da taxa de juros leva em torno de seis meses para afetar a demanda agregada. Os efeitos das reduções recentes ainda não podem, portanto, ser detectados. Este pode ser um argumento importante para justificar a interrupção da política de queda da taxa, implementado pela Autoridade Monetária.

O caminho a ser trilhado para que se mantenha o processo de redução da taxa de juros com o conseqüente estímulo ao crescimento econômico, sem gerar pressões inflacionárias, é o controle dos gastos do governo pois, além de reduzir o nível de demanda 
da economia, reduz a necessidade de financiamento do setor público o que, por sua vez, facilita ainda mais o processo de redução da taxa de juros. É preciso também apreender que o processo de crescimento econômico sustentado e sem pressões inflacionárias depende da manutenção de patamares elevados de investimento produtivo.

\section{Considerações finais}

Pelas evidências expostas no presente trabalho, a economia brasileira está passando por um processo saudável de redução do nível de juros da economia. No entanto, isso se deve principalmente ao bom desempenho da economia mundial e não às políticas econômicas adotadas pelo governo.

Pelo contrário, o aumento dos gastos do governo, que não tem se mostrado saudável, pode abortar tal processo de redução da taxa de juros. Como a taxa de juros ainda está muito elevada quando comparada ao nível das demais economias, esta ainda continua a ser um entrave ao crescimento.

Não podemos também esquecer que o FED promoveu uma queda $0,5 \%$ em sua taxa de juros, elevando, portanto, o diferencial. Este movimento já promoveu uma realocação de recursos, cujo efeito imediato fez-se sentir na intensificação da absurda valorização cambial e na melhora no preço das ações mercado doméstico. Manter a política de redução da taxa nominal torna-se fundamental neste momento para conter o processo de valorização do câmbio, assim como a tendência de redução do diferencial de taxa de juros.

No entanto, de uma forma mais geral, caso não ocorram mudanças na política econômica, particularmente na política fiscal, estaremos diante de outro vôo de galinha, onde a manutenção de um processo de bom desempenho econômico depende do elevado crescimento da economia mundial.

\section{Referências bibliográficas}

CURADO, M; NAKABASHI, L (2007). Alternativas para contenção do processo de valorização da taxa de câmbio brasileira. Boletim Economia ê Tecnologia. Publicação do Centro de Pesquisas Econômicas (CEPEC) da Universidade Federal do Paraná, 9: 29-42.

KALDOR, N. (1957). A Model of Economic Growth. The Economic Joumal, 67 (268): 591-624.

KELLER, W. (2004). International Technology Diffusion. Journal of Economic Literature, 42 (3): 752-782. 